\title{
Ocorrência de Aeromonas sp. e microrganismos psicrotróficos e estimativa do prazo de validade comercial de filé de pintado (Pseudoplatystoma coruscans) mantidos sob refrigeração
}

\author{
[Occurrence of Aeromonas sp. and psychrotrophic microorganisms and estimate the shelf \\ life of "pintado" (Pseudoplatystoma coruscans) fillets kept under refrigeration] \\ M. Lanzarin' ${ }^{1}$, E.S. Almeida Filho², D.O. Ritter ${ }^{1}$, C.A. Mello², G.S.S. Corrêa $a^{2}$, C.M.S. Ignácio ${ }^{1}$ \\ ${ }^{1}$ Aluno de pós-graduação - Universidade Federal de Mato Grosso - Cuiabá, MT \\ ${ }^{2}$ Faculdade de Agronomia e Medicina Veterinária - Universidade Federal de Mato Grosso - Cuiabá, MT
}

\section{RESUMO}

Verificou-se a ocorrência de bactérias do gênero Aeromonas e estimou-se o prazo de validade comercial de filés de pintado (Pseudoplatystoma coruscans) com pele, durante estocagem em refrigeração por meio da quantificação de microrganismos heterotróficos aeróbios psicrotróficos e análises físico-químicas para determinação do $\mathrm{pH}$ e detecção de amônia e gás sulfídrico. Foram utilizadas 45 amostras de filé de pintado, com aproximadamente 100 gramas cada, embaladas individualmente em polietileno de alta densidade e armazenadas em câmara frigorífica entre $0^{\circ} \mathrm{C}$ e $3^{\circ} \mathrm{C}$. A cada dois a três dias de estocagem, três unidades de filés foram submetidas a análises microbiológicas e físico-químicas, totalizando 15 análises durante o período de estocagem. As contagens de Aeromonas sp. e microrganismos heterotróficos aeróbios psicrotróficos variaram de 1,89 a $9,47 \log \mathrm{UFC} / \mathrm{g}$ e 0 a $6,54 \log \mathrm{UFC} / \mathrm{g}$, respectivamente. A variação do pH foi de 6,20 a 6,97, e as análises de amônia e gás sulfídrico foram negativas durante todo o período. $\mathrm{O} \mathrm{pH}$ dos filés de pintado atingiu o limite máximo de 6,4 aos 23 dias de estocagem, e estimou-se o seu prazo de validade comercial.

Palavras-chave: peixe, Aeromonas sp., psicrotróficos, Pseudoplatystoma coruscans, vida comercial

\begin{abstract}
This word studied the occurrence of bacteria from genus Aeromonas and estimate the shelf life of "pintado" fish fillets (Pseudoplatystoma coruscans), during cold storage, through the quantification of psychrotrophic aerobic microorganisms, physical and chemical analyses for presence of ammonia and gas sulphide (H2S) and pH as used in 45 samples of "pintado" fillets with approximately 100 grams each, individually packed in high density polyethylene and stored in cold storage $\left(0^{\circ} \mathrm{C}\right.$ to $\left.3^{\circ} \mathrm{C}\right)$. Every $2-3$ days of storage, 3 units of fillets were subjected to microbiological and physicochemical analysis for a total of 15 days during the storage period. The Aeromonas sp. and psychrotrophic microorganisms count varied from 1.89 to $9.47 \mathrm{log} C F U / g$ and 0 to $6.54 \log C F U / g$, respectively. The $\mathrm{pH}$ variation was from 6.20 to 6.97 and ammonia and $H 2 S$ analyses were negative during the whole period. According under Brazilian legislation (Brazil, 1981) estimated the commercial shelf life of "pintado" fillets being 23 days when the $\mathrm{pH}$ reached a value of 6.4. The $\mathrm{pH}$ of the "pintado" fillets reached the maximum limit of 6.4 at 23 days of storage, being its estimated commercial shelf life.
\end{abstract}

Keywords: Aeromonas sp., psychrotrophic, Pseudoplatystoma coruscans, useful life

\section{INTRODUÇÃO}

Em geral, o peixe, como qualquer outro alimento, apresenta uma microbiota própria, principalmente na superfície corporal, vísceras e guelras, coexistindo em equilíbrio biológico no peixe vivo (Ogawa e Maia, 1999; Vieira, 2004). Além de sua microbiota saprófita, inerente ao ambiente, os peixes podem ser contaminados por bactérias patogênicas oriundas não apenas do ambiente aquático, mas também do processamento e da estocagem inadequados.

Recebido em 9 de novembro de 2011

Aceito em 9 de setembro de 2011

E-mail: marilulanzarin@yahoo.com.br 
Espécies do gênero Aeromonas sp. patogênicas são encontradas normalmente na superfície dos peixes, podem multiplicar-se em temperaturas normalmente utilizadas na estocagem e são implicadas como agentes deteriorantes. Além dos microrganismos patogênicos importantes do ponto de vista de saúde pública, existem também os deterioradores que promovem intensa proteólise e lipólise nos tecidos do pescado, reduzindo o prazo de validade comercial normalmente esperado para o produto (Rall et al., 1998; Ogawa e Maia, 1999; Ranzani-Paiva et al., 2004).

Com a despesca, as defesas naturais deixam de existir, passando os demais tecidos a serem infectados após a morte do animal, já que o músculo do peixe vivo é estéril, dando início, no período de estocagem sob refrigeração, às alterações de deterioração, com multiplicação microbiana, elevação do $\mathrm{pH}$ e formação de compostos voláteis como amônia e gás sulfídrico (Ogawa e Maia, 1999).

O Manual do Laboratório Nacional de Referência Animal (Brasil, 1981) prevê os valores de $\mathrm{pH}$ de 5,8 a 6,4 para carnes de pescado próprias para consumo imediato, e acima deste índice em início de decomposição. A atual legislação não estabelece limites para contagem em placas de microrganismos heterotróficos aeróbios psicrotróficos em peixe fresco, no entanto a legislação internacional, para este fim, estabelece o limite máximo de unidades formadoras de colônia em 7,0log por grama (Asseguramento..., 1997). A legislação também não faz referência em relação à pesquisa, identificação e/ou quantificação de bactérias do gênero Aeromonas, nem nas águas e nem em alimentos, sendo que este patógeno já foi descrito como emergente pela Organização Mundial da Saúde (OMS), relacionado a diversas doenças no homem (Rall et al., 1998).

A estimativa do prazo de vida útil dos pescados no comércio varejista, tendo como base a temperatura padrão de $0^{\circ} \mathrm{C}$, é importante para se estabelecer o melhor monitoramento por parte da vigilância sanitária. Em virtude disso e da ausência total de informações sobre peixes comercialmente importantes da região do pantanal, este trabalho teve como objetivo verificar a ocorrência de Aeromonas sp. e estimar o prazo de validade comercial de filé de pintado
(Pseudoplatystoma coruscans) fresco, mantido em embalagem de polietileno, estocado à temperatura de $0^{\circ} \mathrm{C}$ a $3^{\circ} \mathrm{C}$, pela quantificação de microrganismos heterotróficos aeróbios psicrotróficos e análises físico-químicas para determinação do pH e detecção de amônia e gás sulfídrico.

\section{MATERIAL E MÉTODOS}

Logo após a captura, o pescado foi acondicionado em embalagem estéril e colocado em caixa isotérmica contendo gelo, na proporção de 2:1 (gelo: peixe) e, em seguida, encaminhado ao laboratório de inspeção de produtos de origem animal. $O$ pescado foi submetido à inspeção visual para observação de requisitos de qualidade inerentes ao peixe fresco, como: aparência geral saudável, olhos brilhantes dentro da cavidade orbitária, guelras de vermelho intenso e brilhante, musculatura firme, odor e cor característicos de acordo com MAPA (Brasil, 1997). Após a inspeção, foi realizada a lavagem superficial com água clorada (5ppm) e, em seguida, feita filetagem. Os filés com pele, provenientes de três peixes que consistiram nas repetições, foram divididos em 45 porções de aproximadamente 100 gramas cada, as quais constituíram as unidades amostrais, sendo cada uma delas embaladas individualmente em polietileno estéril e armazenadas em câmara frigorífica à temperatura de $0^{\circ} \mathrm{C} \mathrm{a} 3^{\circ} \mathrm{C}$.

As análises microbiológicas e físico-químicas foram realizadas no primeiro dia de estocagem (dia zero) e a cada dois a três dias de estocagem, totalizando 15 dias de análises dias zero, dois, quatro, seis, oito, 11, 14, 17, 20, 23, 26, 28, 31, 34 e 37. A quantificação e a identificação de bactérias do gênero Aeromonas foram realizadas conforme metodologia descrita por Rall (1998), e a quantificação de microrganismos heterotróficos aeróbios psicrotróficos de acordo com MAPA (Brasil, 2003). As análises físico-químicas para determinação do $\mathrm{pH}$ e detecção de amônia e gás sulfídrico $\left(\mathrm{H}_{2} \mathrm{~S}\right)$ seguiram as normas analíticas do IAL (Métodos..., 2008).

O experimento foi realizado em delineamento inteiramente ao acaso, com 15 tratamentos, que consistiram nos dias de estocagem dos filés e três repetições para cada tratamento, perfazendo um total de 45 amostras. Os resultados encontrados de contagem de Aeromonas sp., microrganismos 
heterotróficos aeróbios psicrotróficos e valores de $\mathrm{pH}$ foram submetidos às análises de variância e regressão, e para as análises de amônia e gás sulfídrico, utilizou-se estatística descritiva dos dados.

\section{RESULTADOS E DISCUSSÃO}

Os valores logaritmos médios totais da contagem de bactérias do gênero Aeromonas estão discriminados na Tab. 1. Observou-se que o crescimento das bactérias apresentou comportamento quadrático significativo, segundo a equação: $y=2,64962+0,473624 x-$ $0,00910471 x^{2}$ (Fig. 1), com máximo crescimento no $26^{\circ}$ dia de estocagem, correspondendo a $8,29 \log U F C / g$, o que demonstra uma multiplicação acentuada durante o período de estocagem até o $26^{\circ}$ dia. Isso destaca sua importância como contaminantes de peixes, e, conforme descrito por Palumbo (1986), trata-se de um agente psicrotrófico, uma vez que pode se multiplicar em temperatura ambiente e também sob refrigeração. Este e outros microrganismos patogênicos, como Yersinia enterocolitica e Listeria monocytogenes, colocam em risco a segurança de alimentos sob refrigeração, podendo, quando ingeridos por meio do pescado, causar gastrenterites em humanos.

Tabela 1. Valores médios da contagem de Aeromonas sp., de microrganismos heterotróficos aeróbios psicrotróficos, de $\mathrm{pH}$ e detecção de amônia e gás sulfídrico de filé de pintado (Pseudoplatystoma coruscans) fresco, mantido em embalagem de polietileno e estocado em câmara frigorífica $\left(0^{\circ} \mathrm{C}\right.$ a $\left.3^{\circ} \mathrm{C}\right)$, de acordo com os dependentes tratamentos (dias de estocagem)

\begin{tabular}{llllll}
$\begin{array}{l}\text { Tratamento } \\
\text { (dia de } \\
\text { estocagem) }\end{array}$ & $\begin{array}{l}\text { Aeromonas sp. } \\
(\log \text { UFC/g) }\end{array}$ & $\begin{array}{l}\text { MHAP } \\
(\log \text { UFC/g) }\end{array}$ & $\mathrm{pH}$ & Amônia & Gás sulfídrico \\
\hline 0 & 1,84 & 0 & 6,33 & Negativo & Negativo \\
2 & 4,00 & 0 & 6,30 & Negativo & Negativo \\
4 & 4,42 & 0 & 6,26 & Negativo & Negativo \\
6 & 5,59 & 0 & 6,20 & Negativo & Negativo \\
8 & 5,76 & 0 & 6,27 & Negativo & Negativo \\
11 & 6,86 & 1,12 & 6,30 & Negativo & Negativo \\
14 & 7,65 & 3,36 & 6,30 & Negativo & Negativo \\
17 & 7,83 & 4,60 & 6,30 & Negativo & Negativo \\
20 & 9,47 & 5,40 & 6,37 & Negativo & Negativo \\
23 & 8,99 & 5,76 & 6,43 & Negativo & Negativo \\
26 & 8,29 & 5,92 & 6,57 & Negativo & Negativo \\
28 & 7,56 & 5,96 & 6,67 & Negativo & Negativo \\
31 & 8,12 & 6,00 & 6,60 & Negativo & Negativo \\
34 & 8,53 & 6,42 & 6,97 & Negativo & Negativo \\
37 & 8,35 & 6,54 & 6,77 & Negativo & Negativo \\
\hline
\end{tabular}

MHAP: microrganismos heterotróficos aeróbios psicrotróficos.

Estudos realizados por Ali et al. (1992) com a carpa (Ciprinus carpio carpio) estocada entre camadas de gelo, na Índia, indicaram que Aeromonas sp. foi o microrganismo mais implicado no processo de deterioração e produção de gás sulfídrico, constatando a importância dessas bactérias como agentes deteriorantes de peixes. Britto et al. (2007), ao avaliarem a deterioração bacteriológica do jaraqui inteiro (Semaprochilodus spp.) conservado em gelo, também constataram o comportamento deteriorador de Aeromonas sp. a partir de 21 dias de armazenamento sob refrigeração. Assim, o crescimento acentuado de
Aeromonas sp. observado neste estudo, pode estar relacionado ao processo de deterioração dos filés de pintado ( $P$. coruscans). Rall et al. (1998), ao analisarem 50 amostras de pintado de peixarias da cidade de São Paulo, encontraram $48 \%$ de amostras positivas para Aeromonas, de onde isolaram A. caviae, A. hydrophila e A. sobria.

A caracterização das espécies de Aeromonas é apresentada na Tab. 2. Podem-se destacar os resultados encontrados para $A$. caviae, $A$. hydrophila e $A$. sobria, que são as espécies de maior relevância nos últimos anos, as quais estão 
associadas à patologia em humanos, como infecções gastrintestinais e não intestinais como peritonite, infecção do trato urinário, meningite e septicemia, conforme citações de Deodhar et al. (1991), Singh e Sanyal (1997) e Rall et al. (1998). Além disso, Kirov (1993) concluiu que algumas linhagens de Aeromonas spp. são enteropatogênicas, e possuem habilidade de produzir enterotoxinas, citotoxinas, hemolisinas e/ou habilidade de invadir células epiteliais.

Tabela 2. Prevalência de espécies de Aeromonas spp. em filé de pintado (Pseudoplatystoma coruscans) fresco, mantido em embalagem de polietileno sob refrigeração

\begin{tabular}{lc}
\hline Microrganismo isolado & Amostras (\%) \\
\hline Aeromonas $s p$ & $26,7 \%$ \\
A. trota & $26,7 \%$ \\
A. shigelloides & $24,4 \%$ \\
A. hydrophila & $6,7 \%$ \\
A. caviae & $6,7 \%$ \\
A. jandaei & $2,2 \%$ \\
A. veronni biot. sobria & $2,2 \%$ \\
\hline $\mathrm{n}=45$
\end{tabular}

Resultados semelhantes foram encontrados por Hanninen et al. (1997), que, ao analisarem 41 amostras de pescado de água doce, encontraram $65,8 \%$ dos peixes e $4,9 \%$ dos camarões positivos para Aeromonas sp. Pereira et al. (2004) estudaram mexilhões (Perna perna) in natura e pré-cozidos no Rio de Janeiro e isolaram $A$. media, A. hydrophila, A. caviae, A. veronii biot.veronii, A. sobria, A. trota, A. schubertii, A. jandaei e A. veronii biot. sobria. Mello (2008), ao estudar a qualidade microbiológica de Brycon microleps (piraputanga) capturado na bacia do rio Cuiabá, MT, encontrou 33\% das amostras de encéfalo e fígado de peixes de rio positivas para Aeromonas sp., sendo isoladas A. hydrophila, A. sobria e A. caviae, resultados semelhantes ao deste estudo.

A contagem de microrganismos heterotróficos aeróbios psicrotróficos variou de 0 a 6,54logUFC/g, entretanto não foi observada multiplicação nos primeiros dias de estocagem, mas, a partir do $11^{\circ}$ dia, houve aumento progressivo da população destes microrganismos, seguindo uma curva de comportamento quadrático em relação ao crescimento microbiano, de acordo com a equação: $\mathrm{y}=-4,76243+0,716681 \mathrm{x}-$ $0,0114204 \mathrm{x}^{2}$ (Fig. 2), com crescimento máximo no $31^{\circ}$ dia de estocagem. A não multiplicação no início do período de estocagem pode ser atribuída ao fato de essas bactérias utilizarem, para seu desenvolvimento, compostos não proteicos derivados do processo de deterioração do peixe e, também, à capacidade de se adaptarem a baixas temperaturas, conforme descrito por Gram e Huss (1996). Isso também foi confirmado por Lyhs et al. (2001), Batista et al. (2004), Borges et al. (2006) e Britto et al. (2007), que analisaram a qualidade de pescados e observaram contagens elevadas de microrganismos heterotróficos aeróbios psicrotróficos ao final do período de estocagem, o que demonstra a importância destes microrganismos no prazo comercial dos produtos.

Rodrigues et al. (2008), ao estudarem a qualidade da tilápia (Oreochromis niloticus) eviscerada e estocada em gelo, observaram contagens de microrganismos heterotróficos aeróbios psicrotróficos entre 0 e 9,40 log UFC/g em músculo com pele, e entre 0 e 7,90logUFC/g em músculo sem pele, durante 28 dias de estocagem. O limite de 7,0logUFC/g foi atingido aos 18 dias em ambos os grupos, fato não observado na presente pesquisa, em que a contagem de psicrotróficos se manteve abaixo deste limite, que foi atingido ao $37^{\circ}$ dia.

Embora a legislação brasileira ainda não contemple o limite para microrganismos heterotróficos aeróbios psicrotróficos, observa-se que contagens elevadas desse grupo de bactérias contribuem para a redução do prazo de vida comercial em virtude de suas características proteolíticas e lipolíticas e, também, pelo fato de se desenvolverem em baixas temperaturas. Soccol et al. (2005), ao trabalharem com filés de tilápia embalados sob ar atmosférico, verificaram contagens de 2,0logUFC/g e $7,25 \log \mathrm{UFC} / \mathrm{g}$, respectivamente, no primeiro e no $20^{\circ}$ dia de estocagem sob refrigeração. Esses resultados de altas taxas de bactérias Aeromonas sp. e psicrotróficas observadas em diversos trabalhos reforça a necessidade de se aprofundar estudos no sentido de instituir limite máximo desses microrganismos para peixe fresco na legislação brasileira.

A variação do $\mathrm{pH}$ dos filés de pintado durante o período de armazenamento sob refrigeração foi de 6,2 a 6,97 (Tab. 1). Essa variação apresentou 
comportamento quadrático em função dos dias de estocagem segundo a equação: $y=6,29764$ $0,00883328 x+0,000683374 x^{2}$ (Fig. 3), ou seja, no início houve pequenas variações, decrescentes até o $6,5^{\circ}$ dia, possivelmente em razão da formação anaeróbica de ácido lático, e crescentes a partir daí, aumentando até valores de 6,97 aos 34 dias, o que pode ser consequência da multiplicação de microrganismos e degradação dos compostos com produção de radicais alcalinos, conforme descrito por Ogawa e Maia (1999).

Resultados semelhantes foram encontrados por Rong et al. (2009), que, ao estudarem tilápia inteira não eviscerada, inteira eviscerada e filés estocados sob refrigeração $\left(5^{\circ} \mathrm{C} \pm 1^{\circ} \mathrm{C}\right)$, observaram decréscimo no $\mathrm{pH}$ dos três lotes nos primeiros dias e, a partir daí, aumento significativo. Batista et al. (2004) e Borges et al. (2006) também observaram aumento do $\mathrm{pH}$ de peixes em função do tempo de estocagem de 26 , 23 e 20 dias, respectivamente. O limite máximo aceitável de 6,4 para pH, determinado pelo manual do Lanara (Brasil, 1981) como produto próprio para consumo, foi atingido no $23^{\circ}$ dia de estocagem dos filés sob refrigeração, ou seja, encontrou-se $\mathrm{pH}$ de 6,43 (Tab. 1), e este foi o determinante do prazo de validade comercial de tal estudo.

Este resultado confirma os já obtidos por Rodrigues et al. (2008), que, ao trabalharem com tilápia eviscerada, verificaram que o limite de 6,4 foi alcançado aos 18 dias de estocagem em gelo. Esses autores encontraram variações de 5,9 a 7,29 e 5,8 a 7,38 no músculo com pele e músculo sem pele, respectivamente.

Nas análises físico-químicas para a detecção de amônia e gás sulfídrico, $100 \%$ das amostras foram negativas (Tab. 1) no $23^{\circ}$ dia, determinadas de acordo com a análise de $\mathrm{pH}$. Quanto a estas características, as amostras podem ser consideradas aptas ao consumo, conforme o Regulamento de Inspeção Industrial e Sanitária de Produtos de Origem Animal (Brasil, 1952), que determina ausência destes compostos para pescado fresco.

\section{CONCLUSÕES}

Para filé de pintado, estocado à temperatura de $0^{\circ} \mathrm{C}$ a $3^{\circ} \mathrm{C}$, o crescimento de bactérias do gênero Aeromonas até o $26^{\circ}$ dia de estocagem sugere que a temperatura não é fator limitante para este microrganismo. A presença de amônia e de gás sulfídrico e a contagem de microrganismos heterotróficos aeróbios psicrotróficos por não atingirem o limite máximo permitido até o $31^{\circ}$ dia de estocagem, sugerem que não se devem usar esses parâmetros na avaliação do produto.

\section{AGRADECIMENTOS}

À coordenação de Aperfeiçoamento de Pessoal de Nível Superior (CAPES), pela concessão da bolsa de estudos.

\section{REFERÊNCIAS BIBLIOGRÁFICAS}

ALI, A.; KARUNASAGAR, I. Bacteriological changes during iced storage of the tropical fresh water carp Labeo rohita. Fish. Res., v.13, p.189197, 1992.

ASSEGURAMIENTO de La calidad de los productos pesqueros: FAO, Roma, 1997. 174p. (Documento técnico de pesca, 334).

BATISTA, G.M.; LESSI, E.; KODAIRA, M. et al. Alterações bioquímicas post-mortem de matrinchã Brycon cephalus procedente da piscicultura, mantido em gelo. Cienc. Tecnol. Aliment., v.24, p.573-581, 2004.

BORGES, A.; FREITAS, M. Q.; FRANCO, R.M. et al. Qualidade da corvina (Micropogonias furnieri) inteira em diferentes períodos de estocagem à temperatura de $0^{\circ} \mathrm{C}$. Rev. Bras. Cienc. Vet., v.13, p.194-196, 2006.

BRASIL. Ministério da Agricultura. Decreto 30691 de 29 de março de 1952, que dispõe sobre o regulamento industrial de inspeção sanitária de produtos de origem animal. Diário Oficial da União. Brasília, DF, 1952.

BRASIL. Ministério da Agricultura. Laboratório Nacional de Referência Animal. Portaria 1 de 7 de outubro de 1981, que aprova os métodos analíticos oficiais para controle de produtos de origem animal e seus ingredientes. Diário Oficial da União. Brasília, DF, v.2, cap. 11, 1981. 
BRASIL. Ministério da Agricultura Pecuária e Abastecimento. Portaria 185 de 13 de maio de 1997, que aprova o Regulamento Técnico de Identidade e Qualidade de peixe fresco (inteiro e eviscerado). Diário Oficial da União. Brasília, DF, 1997.

BRASIL. Ministério da Agricultura, Pecuária e Abastecimento. Instrução Normativa 62 de 26 de agosto de 2003, que oficializa os métodos analíticos para análises microbiológicas para controle de produtos de origem animal e água. Diário Oficial da União. Brasília, DF, 2003.

BRITTO, E.N.; LESSI, E.; CARDOSO, A.L. et al. Deterioração bacteriológica do jaraqui, Semaprochilodus spp. capturado no estado do Amazonas e conservado em gelo. Acta Amaz., v.37, p.457-464, 2007.

DEODHAR, L.P.; SARASWATHI, K.; VARUDKAR, A. Aeromonas spp. and their association with human diarrhoea disease. $J$. Clin. Microbiol., v.29, p.853-856, 1991.

GRAM, L.; HUSS, H.H. Microbiological spoilage of fish and fish products. Int. J. Food Microbiol., v.33, p.121-137, 1996.

HANNINEN, M.L.; OIVANEN, P.; KOSKI, V.H. Aeromonas species in fish, fish-eggs, shrimp and freshwater. Int. J. Food Microbiol., v.34, p.17-26, 1997.

KIROV, M.S. The public health significance of Aeromonas spp. in foods. Int. J. Food Microbiol., v.20, p.179-198, 1993.

LYHS, U.; LAHTINEN, J.; AHOMAA, M.F. et al. Microbiological quality and shelf life of vacuum packaged, 'gravad' rainbow trout stored at 3 and $8^{\circ}$ C. Int. J. Food Microbiol., v.70, p.221-230, 2001.

MELLO, C.A. Qualidade microbiológica do Brycon microleps (piraputanga) capturado na bacia do rio Cuiabá e de cultivo no estado do Mato Grosso. 2008. 111f. Tese (Doutorado em Ciência Veterinária) - Universidade Federal Rural de Pernambuco, Recife.

MÉTODOS físico-químicos para análises de alimentos. São Paulo: Instituto Adolfo Lutz, 2008. p.83-158.
OGAWA, M.; MAIA, E.L. Manual de pesca: ciência e tecnologia do pescado. São Paulo: Varela, 1999. 430p.

PALUMBO, S.A. Is refrigeration enough to restain foodborne pathogens? J. Food Prot., v.49, p. 1003-1009, 1986.

PEREIRA, C.S.; POSSAS, C.A.; VIANA, C.M. et al. Aeromonas spp. e Plesiomonas shigelloides isoladas a partir de mexilhões (Perna perna) in natura e pré-cozidos no Rio de Janeiro - RJ. Cienc. Tecnol. Aliment., v.24, p.562-566, 2004.

RALL, V.L.M.; PEDROSO, D.M.M.; HEIDTMANN, S. Aeromonas species isolated from fish (Pseudoplatystoma sp.), virulence factors and drug susceptibility. Rev. Microbiol., v.29, p.222-227, 1998.

RANZANI-PAIVA, M.J.T.; TAKEMOTO, R.M.; LIZAMA, M.L.A.P. Sanidade de organismos aquáticos. São Paulo: Varela, 2004.

RODRIGUES, T.P.; FREITAS, M.Q.; MARSICO, E.T. et al. Avaliação da qualidade de tilápia do Nilo (Oreochoromis niloticus) cultivada, eviscerada e estocada em gelo. Rev. Bras. Cienc. Vet., v.15, p.67-71, 2008.

RONG, C.; CHANG-HU, X.; QI, L.; BANGZHONG, Y. Microbiological, chemical and sensory assessment of (I) whole ungutted, (II) whole gutted and (III) filleted tilapia (Oreochromis niloticus) during refrigerated storage. Int. J. Food Sci. Technol., v.44, p.22432248, 2009.

SINGH, D.V.; SANYAL, S.C. Production of haemolysis and is correlation with enterotoxicity in Aeromonas spp. J. Med. Microbiol., v.37, p.262-267, 1997.

SOCCOL, M.C.H.; OETTERER, M.; GALLO, C.R. et al. Effects of modified atmosphere and vacuum on the shelf-life of tilapia (Oreochoromis niloticus) fillets. Braz. J. Food Technol., v.8, p.7-15, 2005.

VIEIRA, R.H.S.F. Microbiologia, higiene e qualidade do pescado: teoria e prática. São Paulo: Varela, 2004.380p. 